Available online on 21.05.2018 at http://jddtonline.info
Journal Of Drug Delivery and Therapeutics
Open Access to Pharmaceutical and Medical Research
(2011-18, publisher and licensee JDDT, This is an Open Access article which permits unrestricted non-
commercial use, provided the original work is properly cited

Open $\bigcirc$ Access

Review Article

\title{
GASTRO-RETENTIVE FLOATING BEADS A NEW TREND OF DRUG DELIVERY SYSTEM
}

\author{
Monika Setia, Kapil Kumar*, Deepak Teotia \\ Global Institute of Pharmaceutical Education and Research, Kashipur, Uttarakhand, India
}

\begin{abstract}
The recent scientific and patented literature concluded that an increased interest in novel dosage forms which retained in the stomach for prolong and predictable period of time has been shown. Various technological attempts have been made in the research and development of rate controlled oral drug delivery systems to overcome physiological diversities, as short gastric residence times and unpredictable gastric emptying times using gastro retentive drug delivery system. The present study attempts to give an insight into the gastro-retentive drug delivery systems, and gastric floating dosage forms, in particular. These have attracted the interest of many formulators due to their advantages over the conventional drug delivery systems, recently. The study highlights these advantages with reference to the various types of gastro retentive drug delivery systems, as well as provides an overview of the recent advances that have taken place in this arena. It is a well known fact that differences in gastric physiology such as, gastric $\mathrm{pH}$ and motility exhibit both intra as well as inter-subject variability demonstrating significant impact on gastric retention time and drug delivery behavior. Various attempts have been made to develop gastroretntive systems. Several approaches are currently utilized in the prolongation of the GRT, including floating drug livery system, swelling and expanding systems, polymeric Bioadhesive systems, high- density systems, modified-shape systems and other delayed gastric emptying devices. Floating dosage forms are emerging as a promising dosage forms. Floating dosage forms can be prepared as tablets, capsules by adding suitable ingredients as well as by adding gas generating gent. In this review various techniques used in floating dosage forms along with current and recent developments of stomach specific floating drug delivery systems for gastro retention are discussed.
\end{abstract}

Keywords: Floating drug delivery systems, floating dosage forms, gastric residence time.

Article Info: Received 10 Feb, 2018; Review Completed 02 May 2018; Accepted 21 May 2018; Available online 22 May 2018

Cite this article as:

Setia M, Kumar K, Teotia D, Gastro-retentive floating beads a new trend of drug delivery system, Journal of Drug Delivery and Therapeutics. 2018; 8(3):169-180 DOI: http://dx.doi.org/10.22270/jddt.v8i3.1717

*Address for Correspondence:

Kapil Kumar, Global Institute of Pharmaceutical Education and Research, Kashipur, Uttarakhand, India

\section{INTRODUCTION}

Oral administration is the most convenient and preferred means of any drug delivery to the systematic circulation. Oral controlled release drug delivery have recently been of increasing interest in pharmaceutical field to achieve improved therapeutic advantages, such as ease of dosing administration, patient compliance and flexibility in formulation. Drugs that are easily absorbed from gastrointestinal tract (GIT) and have short half-lives are eliminated quickly from the systemic circulation. Frequent dosing of these drugs is required to achieve suitable therapeutic activity. To avoid this limitation, the development of oral sustained-controlled release formulations is an attempt to release the drug slowly into the gastrointestinal tract (GIT) and maintain an effective drug concentration in the systemic circulation for a long time $^{1}$. After oral administration, such a drug delivery would be retained in the stomach and release the drug in a controlled manner, so that the drug could be supplied continuously to its absorption sites in the gastrointestinal tract (GIT). These drug delivery systems suffer from mainly two adversities: the short gastric retention time (GRT) and unpredictable short gastric emptying time (GET), which can result in incomplete drug release from the dosage form in the absorption zone (stomach or upper part of small intestine) leading to diminished efficacy of administered dose. To formulate a sitespecific orally administered controlled release dosage form, it is desirable to achieve prolong gastric residence time by the drug delivery. Prolonged gastric retention improves bioavailability, increases the duration of drug release, reduces drug waste, and improves the drug 
solubility that are less soluble in a high $\mathrm{pH}$ environment $^{2}$. Also prolonged gastric retention time (GRT) in the stomach could be advantageous for local action in the upper part of the small intestine e.g. treatment of peptic ulcer, etc. Gastro retentive drug delivery is an approach to prolong gastric residence time, thereby targeting site-specific drug release in the upper gastrointestinal tract (GIT) for local or systemic effects. Gastro retentive dosage forms can remain in the gastric region for long periods and hence significantly prolong the gastric retention time (GRT) of drugs. Over the last few decades, several gastro retentive drug delivery approaches being designed and developed, including: high density (sinking) systems that is retained in the bottom of the stomach, low density (floating) systems that causes buoyancy in gastric fluids, mucoadhesive systems that causes bioadhesion to stomach mucosa, unfoldable, extendible, or swellable systems which limits emptying of the dosage forms through the pyloric sphincter of stomach, super porous hydrogel systems, magnetic systems etc. The current review deals with various gastro retentive approaches that have recently become leading methodologies in the field of site-specific orally administered controlled release drug delivery systems.

\section{BASIC PHYSIOLOGY OF GASTROINTESTINAL TRACT}

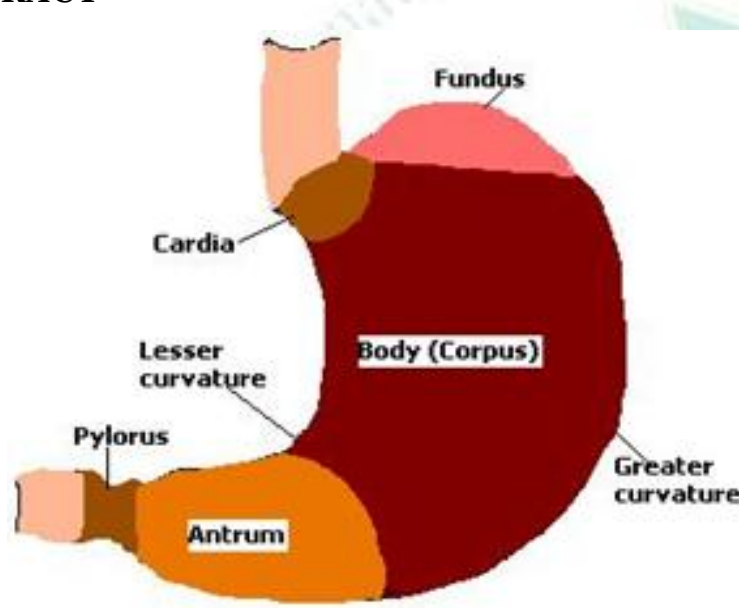

Figure 1: Anatomy of Stomach
Anatomically the stomach is divided into three regions: Fundus, body and antrum (pylorus).

The proximal part forms fundus and body act as reservoir for undigested materials where as the antrum is the main site for mixing motions and act as pump for gastric emptying by propelling actions ${ }^{3}$. Gastric emptying occurs during fasting as well as fed state.

The patent of motility is however distinct in 2 states. During fasting state, inter digestive series of electrical events takes place, which cycles both through stomach and intestine every 2 to 3 hours. This is called the interdigestive myoelectric cycle or migrating myloelectric cycle (MMC), which is further divided into following 4 phases as described by Wilson and Washington (1989) ${ }^{4}$.

1. Phase I (basal phase) lasts from 40 to 60 minutes with contractions.

2. Phase II (pre burst phase) lasts for 40 to 60 minutes with intermittent action potential and contractions. As the phase progress the intensity and frequency also increases gradually.

3. Phase III (burst phase) last for 4 to 6 minutes. It includes intense and regular contractions for short period. It is due to this wave that all the undigested material is swept out of the stomach down to the small intestine. It is also known as the house keeper wave.

4. Phase IV last for 0 to 5 minutes and occurs between phases III and I of 2 consecutive cycles. After the ingestion of a mixed meal, the pattern of contractions changes from fasted to that of fed state. This is also known as digestive motility pattern and comprises continuous contractions as in phase II of fasted state. These contractions results in reducing the size of food particles (to less than $1 \mathrm{~mm}$ ) which are propelled toward the pylorus in a suspension form. During the fed state onset of MMC is delayed resulting in slowdown of gastric emptying rate. Scintigraphic studies determining gastric emptying rates revealed that orally administered controlled release dosage form are subjected to basically two complications that of short gastric residence time and unpredictable gastric emptying rate.

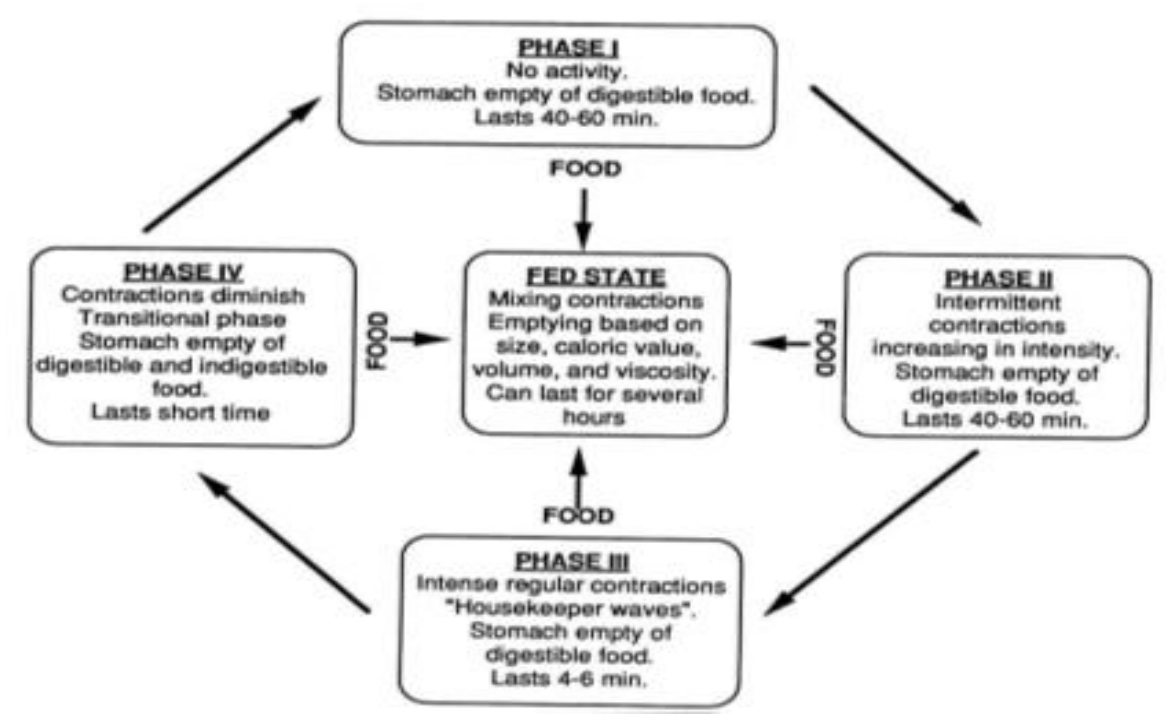

Figure 2: Schematic representation of myloelectric cycle 


\section{Needs for gastric retention}

1) Drugs that are absorbed from the proximal part of the gastrointestinal tract (GIT).

2) Drugs that are less soluble or are degraded by the alkaline $\mathrm{pH}$ they encounters at the lower part of GIT.

3) Drugs that are absorbed due to variable gastric emptying time. Local or sustained drug delivery to the stomach and proximal Small intestine to treat certain conditions.

4) Particularly useful for the treatment of peptic ulcers caused by H.Pylori Infections.

\section{Factors affecting gastric retention}

- Density of dosage form - Density of gastric fluid is reported to be $1.004 \mathrm{gm} / \mathrm{ml}$. The density of the dosage form should be less than this for buoyancy, so that it is retained in the stomach for a longer time. Dosage forms may have a high density in the beginning but float in the stomach due to reduction in density by swelling.

- Composition of meal: Fats, particularly fatty acids inhibit gastric secretion and have a pronounced reductive effect on the rate of emptying. Proteins and starch are shown to have inhibitory effect on gastric emptying, though to a less extent. As the viscosity of the gastric fluids is increased, there is a corresponding decrease in the rate of emptying.

- Caloric content: Gastric residence time can be increased by $4-10 \mathrm{hrs}$ with a meal that is rich in proteins and fats.

- Frequency of the food: - The gastric residence time can increase by $>6 \mathrm{hrs}$ when successive meals are given, compared with a single meal, due to low frequency MMC.

- Size of dosage form: - In general it is known that indigestible solids $>1-2 \mathrm{~mm}$ are retained in the stomach throughout the postprandial period, after which they are emptied by cyclical recurring brust of interdigestive gastric contractions. Many recent studies have shown that non disintegrating tablets as large as $7.0 \mathrm{~mm}$ can be emptied from the human stomach during the postprandial period, while $13.0 \mathrm{~mm}$ tablets are retained until arrival of subsequent sweeping 'housekeeper waves'. This emphasizes the need for size enlargement of dosage forms in the stomach in order to prolong the gastric residence time.

- Sex: - Generally females have a slower gastric emptying rate $\left(\begin{array}{ll}4.6 & 1.2 \mathrm{hrs})\end{array}\right)$ than males (3.40.6hr) regardless of weight, height and body surface area.

- Body posture: - Gastric emptying is favored while standing and by lying on the right side since the normal curvature of the stomach provides a downhill path whereas lying on the left side or in supine position retards it.

- Emotional state of subject: - The influence of emotional factors on gastric motility depending upon whether the emotional experience is of an aggressive or a depressive type.
- Effect of drugs: - Drug that retard gastric emptying includes poorly soluble antacids (Aluminum hydroxide), anticholinergics (Atropine, Propantheline), narcotic analgesics (Morphine) and tricyclic antidepressants (Imipramine, amitryptiline), Metoclopramide, domperidom and cisapride (Anti emetics) stimulates gastric emptying.

- Exercise: - Vigorous physical activity retards gastric emptying.

- Disease states:-Diseases like gastroenteritis, gastric ulcer, pyloric stenosis, diabetes and hypothyroidism retard gastric emptying. Duodenal ulcer and hyperthyroidism promote gastric emptying rate.

- Gastrointestinal pH: - Gastric emptying is retarded at low stomach $\mathrm{pH}$ and promoted at higher or alkaline $\mathrm{pH}$. Chemicals that affect gastrointestinal $\mathrm{pH}$ also alter gastric emptying. The inhibitory effect of various acids on gastric emptying decreases with increase in molecular weight and is in the following order HCL $>$ Acetic $>$ lactic $>$ tartaric $>$ citric. With alkaline solutions, a low base concentration (1\% NaHCO3) increases the gastric emptying rate more than the 1 of higher concentration $(5 \%)$.

\section{Drugs suitable for GRDDS}

1) Drugs acting locally in the stomach E.g. Antacids and drugs for H. Pylori viz., Misoprostol

2) Drugs that are primarily absorbed in the stomach E.g. Amoxicillin

3) Drugs that is poorly soluble at alkaline $\mathrm{pH}$ E.g. Furosemide, Diazepam, Verapamil

4) Drugs with a narrow window of absorption E.g. Cyclosporine, Methotrexate, Levodopa, etc.

5) Drugs which are absorbed rapidly from the GI tract. E.g. Metonidazole, tetracycline.

6) Drugs that degrade in the colon. E.g. Ranitidine, Metformin HCl.

7) Drugs that disturb normal colonic microbes E.g. antibiotics against Helicobacter pylori.

\section{Drugs unsuitable for GRDDS}

1. Drugs that have very limited acid solubility e.g. phenytoin etc.

2. Drugs that suffer instability in the gastric environment e.g. Erythromycin etc.

3. Drugs intended for selective release in the colon. E.g. 5- amino salicylic acid and corticosteroids etc.

\section{Advantages}

1) Improves patient compliance.

2) Bioavailability enhances despite first pass effect because fluctuations in plasma drug concentration is avoided, a desirable plasma drug concentration is maintained by continuous drug release

3) Freedom from incompatibilities between drug and excipients especially with buffers. 
4) Better therapeutic effect of short half life drugs can be achieved.

5) Gastric retention time is increased because of buoyancy.

6) Site specific drug delivery to the stomach can be achieved.

7) Mask the unpleasant odor, taste of drugs and protect the drugs from the environment

8) Freedom from incompatibilities between drugs and excipients especially the buffers and safe handling of toxic substances.

9) Pulsatile release of antibiotics can alleviate evolution of the bacterial resistance. In the vaccine delivery, initial burst followed by delayed release pulses can mimic initial and boost injection, respectively.

10) The local delivery system avoids systemic drug administration for local therapeutic effects and can reduce the related systemic side effects.

11) The volatile drugs can be easily formulated as floating microspheres compared to other conventional dosage forms.

\section{Disadvantages}

1) These systems require a high level of fluid in the stomach for drug delivery to float however this can be overcome by using low density polymers.

2) The release rate of the controlled release dosage form varies from a variety of factors like rate of food transit through the drug.

3) Potential toxicity due to loss of integrity of drugs.

4) The dosage forms should be administered with more amount of water $\quad(200-250 \mathrm{ml})$.

5) Some drugs present in the floating system causes irritation to gastric mucosa.

6) These dosage forms should not be crushed or chewed

\section{APPROACHES FOR GASTRIC RETENTION}

To improve the retention of an oral dosage form in the stomach various approaches have been developed, e.g. floating systems, swelling and expanding systems, bioadhesive systems, altered density systems and other delayed gastric emptying devices. Floating Drug Delivery Systems (FDDS) or Hydrodynamically Balanced systems (HBS) have bulk density lower than gastric fluids and hence remain floating in the stomach for a prolonged period of time ${ }^{5}$. The drug is slowly released from the floating system at a desired rate without fluctuations in plasma drug concentration thus leading to an increase in the gastric residence time (GRT).After complete release of drug from the delivery system, the residual is expelled from the stomach. To localize delivery device within a cavity of body, bioadhesive systems are usually formulated. In these systems, bioadhesion is achieved by using bioadhesive polymers which adhere to the epithelial surface of gastrointestinal tract. The formation of hydrogen and electrostatic bonding at the mucus polymer interface leads to bioadhesion. Swellable systems are a type of gastro-retentive dosage forms which swell in the stomach to an extent that prevents its exit through the pyloric sphincter resulting in the retention of swellable system in the stomach for a prolonged period of time. Altered density gastro-retentive dosage forms includes systems that have density either greater or lower than the stomach contents leading to an increase in GRT and hence drug release for a prolonged time period.

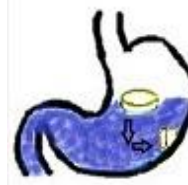

Bioadhesive system
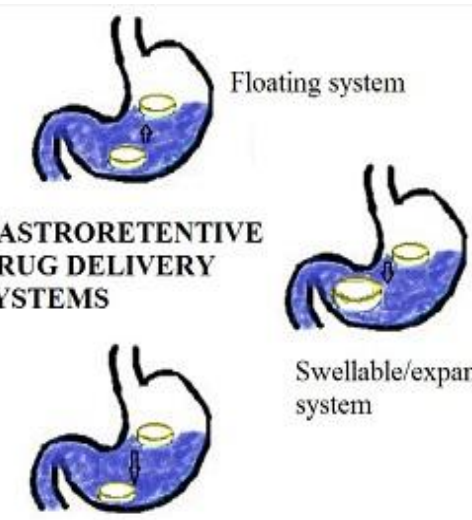

High Density system
Swellable/expandable system
Figure 3: Different drug delivery system

\section{A) High Density Systems}

The density of the pellets must exceed that of normal stomach content $(1.004 \mathrm{gm} / \mathrm{cm} 2)^{6}$. For preparing such formulations, drug can be coated on a heavy core or mixes with heavy inert materials such as barium sulfate, titanium dioxide, iron power and oxide. The weighed pellets can then be covered with a diffusion-controlled membrane. Other delayed emptying approaches of interest include same feeding of indigestible polymers or fatty acid salts that change the motility pattern of the stomach to a fed state, thereby decreasing the gastric emptying rate and permitting considerable prolongation of drug release.

\section{B) Swelling and expanding system}

One way to retain a dosage form in the stomach is by increasing its size. The stomach discharges its contents through the pylorus in to the intestine. If the dosage form can attain a size larger than that of the pylorus it can be retained in the stomach for a long time. Swelling type dosage forms are such that after swallowing these products swell to a extent that prevents their exit from the stomach through the pylorus as a result the dosage form is retained in the stomach for a long period of time. These systems may be referred to as "plug type system" since they exhibit a tendency to remain lodged at the pyloric sphincter.

\section{C) Bioadhesive Systems}

These systems are essentially based on bioadhesive polymers, which adhere to the mucin and / or epithelial surface. Bioadhesive polymers can bind mucus as well as non-mucus membranes. If bioadhesion is restricted to mucosal surface it is called mucoadhesion. Non-specific bioadhesive systems bind to mucin and epithelial surface by non-specific interaction between polymer particle and intestinal surfaces ${ }^{7}$. Specific bioadhesive 
systems are designed by attaching a ligand to polymer particles, the ligand then recognizes and attaches to a specific area of the mucosal surface. Mucoadhesive controlled release systems increase the effectiveness of the drug by maintaining the drug concentration in therapeutic level, inhibiting the dilution of drugs in body fluids, and allowing targeting and localization of drugs at specific site. The duration of contract and intimacy between polymer-drug particles and mucosal surface is increased by mucoadhesion.

Lecithin is the most commonly used ligand for specific bioadhesion. Nonspecific bioadhesion mainly depends on the nature of polymer used for the system. Various polymers such as poly (acrylates), poly (lactic acid) chitosan, alginates, polystyrenes and sodium hyaluronate are reportedly bioadhesive in nature.

\section{D) Floating Drug Delivery systems and its mechanism:}

Davis in 1968 first described the FDDS. Floating drug delivery systems (FDDS) have bulk density lesser than gastric fluids, so they remain buoyant in the stomach without affecting the gastric emptying rate for a prolonged period of time. While the system is floating on the gastric contents, the drug is released slowly at the desired rate from the system. After release of drug, the residual system is emptied from the stomach. This results in an increased GRT and a better control of the fluctuations in plasma drug concentration. However, besides a minimal gastric content needed to allow the proper achievement of the buoyancy retention principle, a minimal level of floating force $(F)$ is also required to keep the dosage form reliably buoyant on the surface of the meal. To measure the floating force kinetics, a novel apparatus for determination of resultant weight has been reported in the literature. The apparatus operates by measuring continuously the force equivalent to $\mathrm{F}$ (as a function of time) that is required to maintain the submerged object. The object floats better if $\mathrm{F}$ is on the higher positive side as shown in figure. This apparatus helps in optimizing FDDS with respect to stability and durability of floating forces produced in order to prevent the drawbacks of unforeseeable intragastric buoyancy capability variations.

\section{$\mathrm{F}=\mathrm{F}$ buoyancy $-\mathrm{F}$ gravity $=(\mathrm{Df}-\mathrm{Ds}) \mathrm{gv}$}

Where, $\mathrm{F}=$ total vertical force, $\mathrm{Df}=$ fluid density,

Ds= object density, $\mathrm{v}=$ volume an

$\mathrm{g}=$ acceleration due to gravity
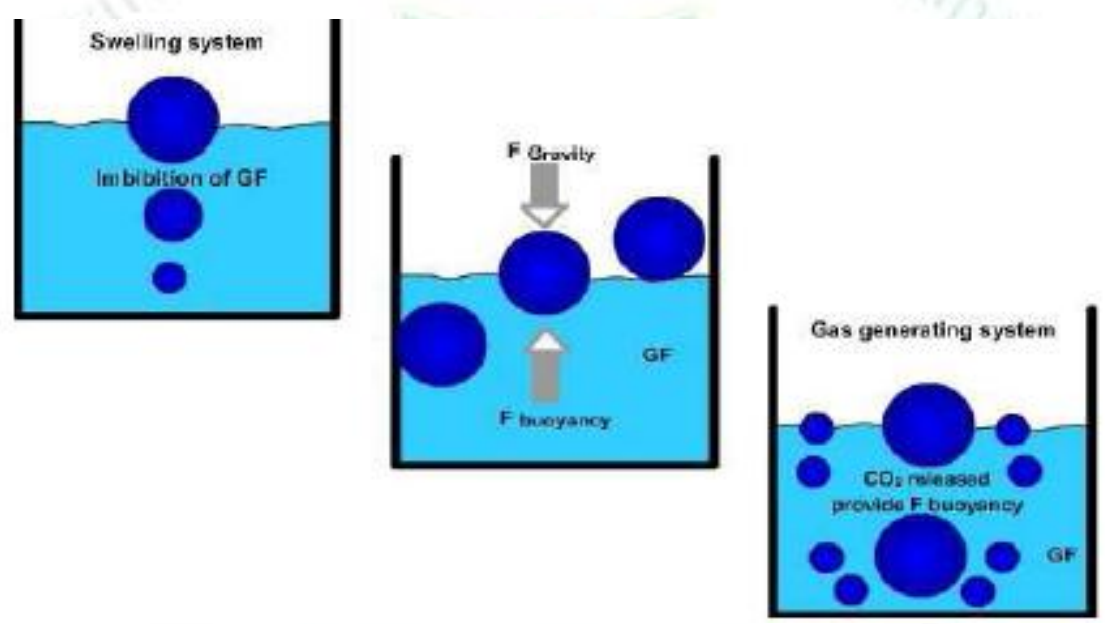

Figure 4: Mechanism of floating systems, GF=Gastric fluid

\section{CLASSIFICATION OF FLOATING SYSTEM ${ }^{8}$}

Based on the mechanism of floating, the floating drug delivery systems are of following types:

\section{A) Non effervescent floating dosage form}

These dosage forms use a gel forming or swellable cellulose type of hydrocolloids, polysaccharides and matrix forming polymers like polycarbonates, polymethacrylate and polystyrene. The formulation is done by mixing the drug and the gel-forming hydrocolloid, after oral administration of this dosage form swells while in contact with gastric fluids attains bulk density of $<1$. The buoyancy of dosage form was attained due to the air entrapment in to the swollen gel like structure acts as a reservoir and allows sustained release of drug through the gelatinous mass. a. Colloidal gel barrier systems

b. Micro porous compartment systems

c. Alginate beads

\section{B) Effervescent floating dosage forms}

These are the matrix types of systems which are prepared by using swellable like methyl cellulose, HPMC and chitosan based polymers as well as various effervescent compounds like Sodium carbonate, Calcium carbonate, Tartaric acid and Citric acid. They are formulated in such a way that when in contact with the acidic gastric contents liberation of $\mathrm{CO} 2$ takes place and gets entrapped in to the swollen hydrocolloids which provides buoyancy to the dosage forms.
i. Volatile liquid containing systems
ii. Gas generating systems 


\section{POLYMERS AND OTHER INGREDIENTS USED}

Numerous polymers and carriers have been utilized for fabrication and to control the drug release in gastric environment ${ }^{10}$. The polymers used in the preparation of floating beads are;

\section{Synthetic polymers.}

2. Natural polymers

i) Polymers: The following polymers used to preparations of floating drugs: HPMC K4 M, Calcium alginate, Eudragit S100 Eudragit RL, Propylene foam, Eudragit RS, ethyl cellulose, poly methyl methacrylate, Methocel K4M, Polyethylene oxide, \% Cyclodextrin, HPMC 4000, HPMC 100, CMC, Polyethylene glycol, polycarbonate, PVA, Polycarbonate, Sodium alginate, HPC-L, HPC, Eudragit S, HPMC, Metolose S.M. 100, PVP, HPCH, HPC-M, HPMC K15, Polyox, HPMC K4, Acrylic polymer E4 M and Carbopol.

ii) Inert fatty materials (5 - 75\%): Edible, inert fatty materials having a specific gravity of less than one can be used to decrease the hydrophilic property of formulation and hence increase buoyancy. E.g. Beeswax, fatty acids, long chain fatty alcohols, Gelucires ${ }^{\circledR} 39 / 01$ and 43/01.

iii) Effervescent agents: Sodium bicarbonate, citric acid, tartaric acid, Di-SGC (Di-Sodium Glycine Carbonate, CG (Citroglycine).

iv) Release rate accelerants (5 - 60\%): eg. lactose, mannitol. v) Release rate retardants (5 - 60\%): eg. Dicalcium phosphate, talc, magnesium stearate

vi) Buoyancy increasing agents (upto 80\%): eg. Ethyl cellulose

vii) Low density material: Polypropylene foam powder (Accurel MP 1000®).

\section{Role of Polymers in Floating drug delivery}

The currently available polymer-mediated non effervescent and effervescent FDDS, designed on the basis of delayed gastric emptying and buoyancy principles, appear to be an effective and rational approach to the modulation of controlled oral drug delivery. This is evident from the number of commercial products and a myriad of patents issued in this field ${ }^{11}$. The FDDS become an additional advantage for drugs that are absorbed primarily in the upper segments of GI tract, i.e., the stomach, duodenum and jejunum. Some of the unresolved, critical issues related to the rational development of FDDS include:-

(1) The quantitative efficiency of FDDSs in the fasted and fed states;

(2) The role of buoyancy in enhancing GRT of FDDS; and

(3) The correlation between prolonged GRT and SR/PK characteristics.

Table 1: Types of Polymers with Examples

\begin{tabular}{|l|l|l|}
\hline Polymer & Sub Type & Examples \\
\hline \multirow{3}{*}{$\begin{array}{l}\text { Synthetic } \\
\text { polymer }\end{array}$} & Biodegradable & $\begin{array}{l}\text { Lactides, glycosides and their co polymers. Poly alkyl } \\
\text { cyanoacrylates, polyanhydrides }\end{array}$ \\
\cline { 2 - 3 } & Non-biodegradable & $\begin{array}{l}\text { Polymethyl methacrylate, Acrolin, Glycidyl } \\
\text { methacrylate, epoxy polymers }\end{array}$ \\
\hline \multirow{2}{*}{ Natural } & Proteins & Albumin, Gelatin, Collagen \\
\cline { 2 - 3 } & Carbohydrates & Agarose, carragenan, Chitosan, starch \\
\cline { 2 - 3 } & Chemically modified carbohydrates & Poly dextran, poly starch \\
\hline
\end{tabular}

Table 2: Polymers and Their Applications

\begin{tabular}{|l|l|}
\hline Polymer & Application \\
\hline Modified starch, HPMC, Carbopol 974p & Slower release of drug \\
\hline Ethyl cellulose & Controlled release for longer period of time \\
\hline PLGA, chitosan & Vaccine delivery \\
\hline Chitosan coated PLGA polymers & Targeted drug delivery \\
\hline Polyvinyl alcohol, polyacrylidine & Adsorption of harmful substance in blood \\
\hline
\end{tabular}

Table 3: Polymers used in preparations of GRDDS

\begin{tabular}{|l|l|}
\hline Polymers & $\begin{array}{l}\text { HPMC 4000, HPMC 100, HPMC K4M, CMC, PVA, Calcium alginate, Carbopol, } \\
\text { Ethyl cellulose,Eudragit RS and RL, acrylic polymer }\end{array}$ \\
\hline Buoyancy increasing agents & Ethyl cellulose \\
\hline Release rate accelerants & Mannitol, Lactose \\
\hline Release rate retardants & Magnesium Stearate, Dicalcium phosphate, Talc \\
\hline Low density materials & Polypropylene foam powder \\
\hline Inert fatty materials & Fatty acids, Bees wax, \\
\hline Effervescent agents & Tartaric acid, Citric acid, Sodium bicarbonate, Citroglycine \\
\hline
\end{tabular}




\section{METHODS OF PREPARATION OF FLOATING BEADS}

\section{1) Solvent evaporation method}

Floating multiparticulate dosage form was prepared by solvent diffusion and evaporation methods to create the hollow inner core. The polymer is dissolved in an organic solvent and the drug is either dissolved or dispersed in the polymer solution. The solution containing the drug is then emulsified into an aqueous phase containing polyvinyl alcohol to form oil in water emulsion. After the formation of a stable emulsion, the organic solvent is evaporated either by increasing the temperature under pressure or by continuous stirring. The solvent removal leads to polymer precipitation at the $\mathrm{o} / \mathrm{w}$ interface of droplets, forming cavity and thus making them hollow to impart the floating properties. The polymers studied for the development of such systems include Cellulose acetate, Chitosan, Eudragit, Acrycoat, Methocil, Polyacrylates, Polyvinyl acetate, Carbopol, Agar, Polyethylene oxide and Polycarbonates $^{12}$. Furthermore, a novel multi-particulate gastro-retentive drug delivery system based on lowdensity foam powder has been proposed and its performance demonstrated in and. Floating micro particles consisting of Polypropylene foam powder, Verapamil $\mathrm{HCl}$ (as the model drug) and Eudragit RS, Ethylcellulose or Poly (methyl methacrylate) (PMMA) were prepared with an oil-inwater solvent extraction/evaporation method. The drug and releaserate-controlling polymer were dissolved in Methylene chloride. Polypropylene foam powder was then dispersed within this organic phase. The resulting suspension was subsequently emulsified into an external aqueous Poly (vinyl alcohol) solution and agitated with a stirrer to allow microparticle formation. The microparticles were separated by being sieved, washed with water and dried in a desiccator; they were irregular in shape and highly porous. Importantly, the drug encapsulation efficiency was high and almost independent of the theoretical loading of the system. In all cases, good in-and floating behavior was observed. Interestingly, a broad spectrum of release patterns could be obtained with the investigated formulations. Further studies focused on the development of an improved preparation method for this type of low density, foambased, floating micro-particle and also on the demonstration of the system's performances inand.

Major advantages of the suggested novel preparation technique include short processing times, no exposure of the ingredients to high temperatures, the ability to avoid toxic organic solvents and high encapsulation efficiencies (close to 100\%). Floating micro-particles consisting of Polypropylene foam powder, model drug (Chlorpheniramine maleate, Diltiazem $\mathrm{HCl}$, Theophylline or Verapamil $\mathrm{HCl}$ ) and a second polymer [Eudragit RS or Poly(methyl methacrylate)] were prepared by soaking microporous foam particles with an organic solution of the drug and polymer and subsequent drying Good in- and floating behavior was observed in most cases and a broad variety of drug release patterns could be achieved by varying the drug loading and type of second polymer ${ }^{13}$. In addition, the low density micro-particles could be compressed into rapidly disintegrating tablets, providing an easily administrable oral dosage form.

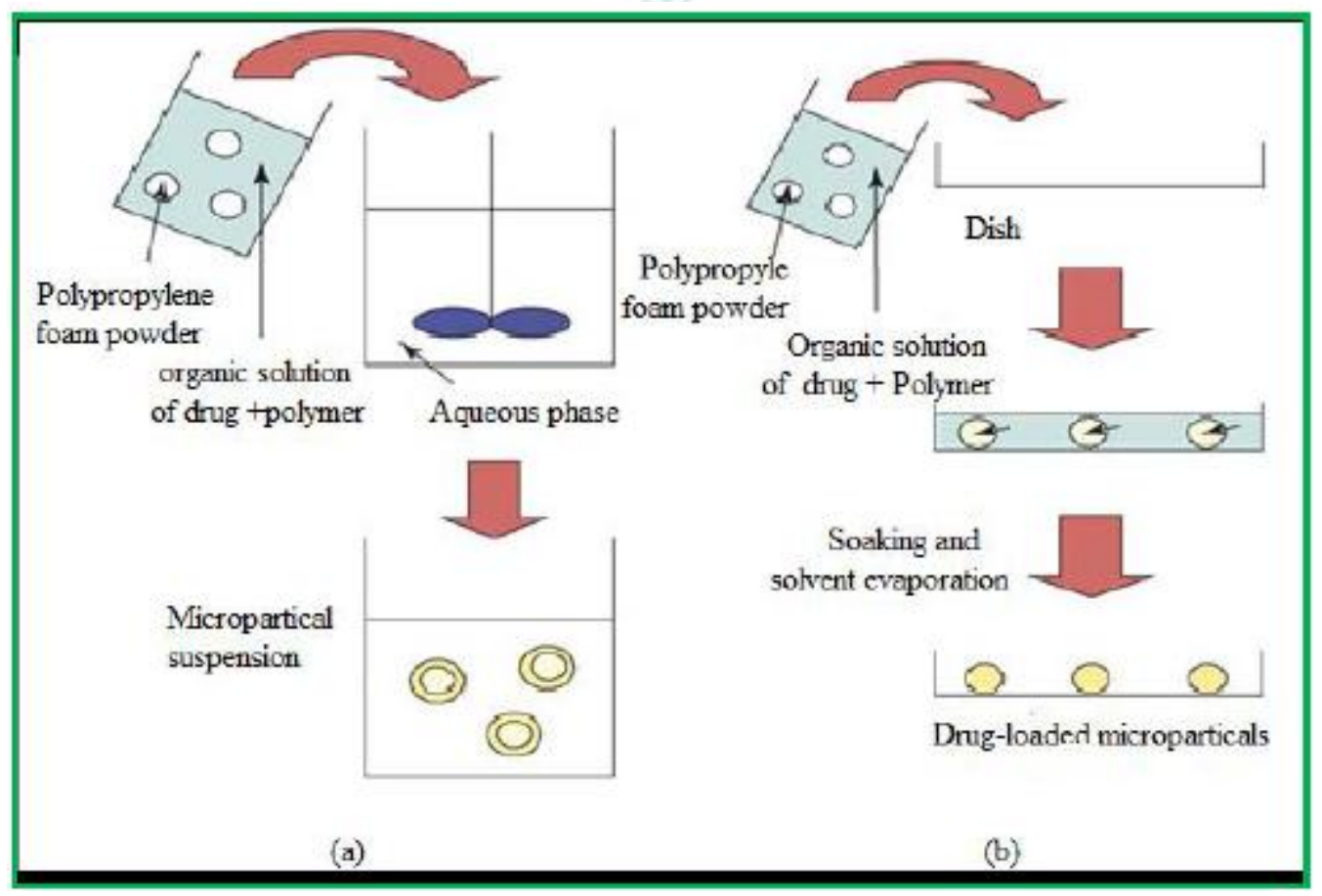

Figure 5: Schematic presentation of the preparation of floating micro-particles based on low-density foam powder, using (a) The solvent evaporation method or (b) The soaking method. 


\section{2) Ionotropic gelation method}

Ionotropic gelation is based on the ability of polyelectrolyte to cross link in the presence of counter ions to form beads. Since, the use of Alginates, Gellan gum, Chitosan and Carboxymethyl cellulose for the encapsulation of drug and even cells, ionotropic gelation technique has been widely used for this purpose ${ }^{14}$. The natural polyelectrolyte inspite, having property of coating on the drug core and acts as release rate retardants contains certain anions on their chemical structure. These anions forms meshwork structure by combining with the polyvalent cations and induce gelation by binding mainly to the anion blocks. The hydrogel beads are produced by dropping a drug-loaded polymeric solution into the aqueous solution of polyvalent cations. Biomolecules can also be loaded into these beads under mild conditions to retain their three dimensional structure. The schematic representation of ionotropic gelation method is shown in figure. El-Gibaly et al developed floating (F) microcapsules containing melatonin (MT), prepared by the ionic interaction of Chitosan and negatively charged surfactant, Sodium dioctyl sulfosuccinate (DOS). The characteristics of the floating microcapsules generated compared with the conventional non-floating (NF) microspheres manufactured from Chitosan and Sodium tripolyphosphate (TPP) were also investigated. Talukder, $\mathrm{R}$. et al developed floatable multiparticulate system with potential for intra gastric sustained drug delivery. Crosslinked beads were made by using calcium and low methoxylated pectin (LMP), which are an anionic polysaccharide, Calcium, LMP and Sodium alginate. Beads were dried separately in an air convection type oven at $40^{\circ} \mathrm{C}$ for 6 hours and in freeze dryer to evaluate the changes in bead characteristics due to process variability ${ }^{15}$. Riboflavin (B-2), Tetracycline (TCN) and Methotrexate (MTX) were used as model drugs for encapsulation. Ionic and nonionic excipients were added to study their effects on the release profiles of the beads.

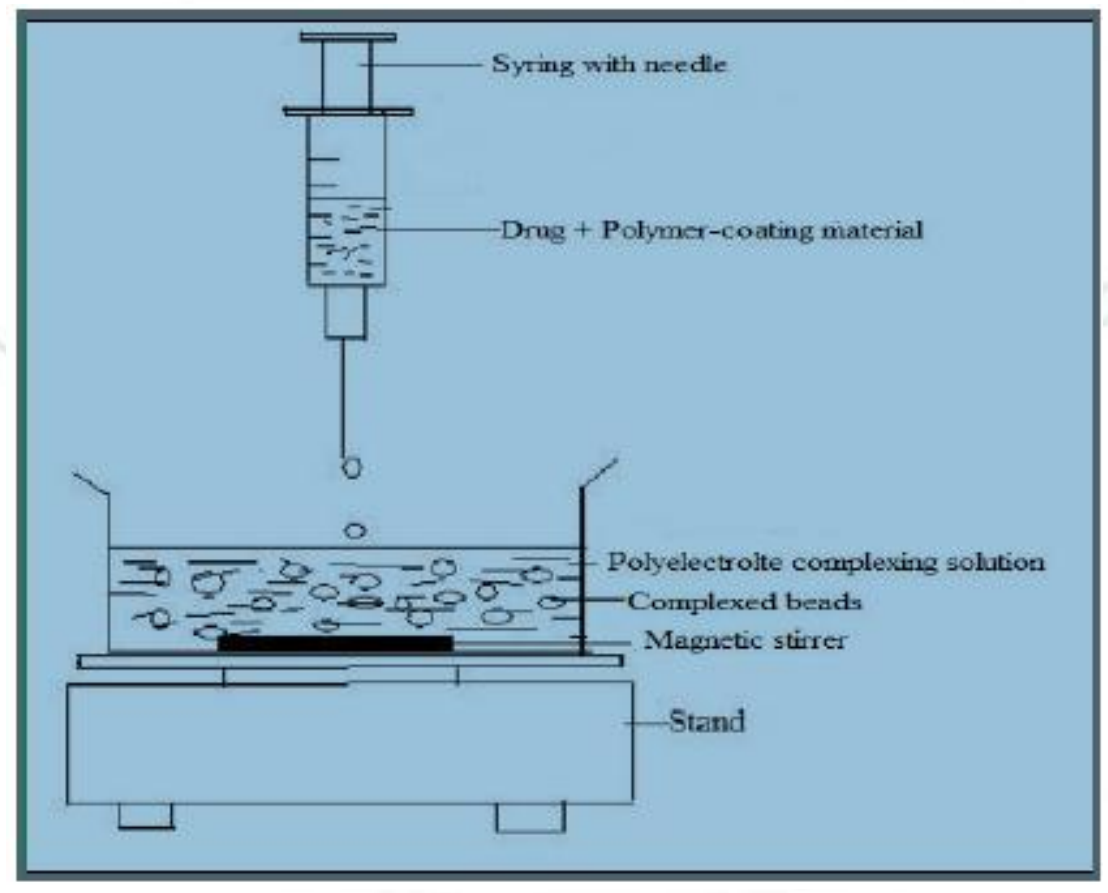

Figure 6: Ionotropic gelation method

\section{Evaluation Tests for Floating Beads}

\section{Angle of Repose:}

Angle of repose helps to evaluate powder flowability by assessing interparticulate friction. In general, the higher is the angle of repose poor is the flowability of powder ${ }^{16}$. The angle of repose of each powder blend was determined by glass funnel method, using following equation,

$$
\tan \theta=\frac{h}{r}
$$

Where, $\theta$ - angle of repose, $\mathrm{h}$ - height of pile above the flat surface, $r$ - radius of the circle formed by the powder blend.

\section{Bulk Density:}

It is ratio of mass to bulk volume. Bulk density may influence dissolution and other properties and depends on the particle size, shape and tendency of particles to adhere together. Bulk density of formulated beads was determined by taking a known mass of beads in a $5 \mathrm{ml}$ graduated measuring cylinder. The cylinder was dropped three times from a height of one inch at an interval of two seconds. The bulk density was calculated by following equation,

\section{Tapped density:}

$$
\text { Bulk density }=\frac{\text { Mass of microspheres }}{\text { Bulk volume }}
$$

Tapped density helps to determine packing geometry and flowability. Tapped density is the volume of powder determined by tapping using measuring cylinder containing weighed amount of sample. Tapped density of beads was calculated by following equation, 


$$
\text { Tapped density }=\frac{\text { Mass of microspheres }}{\text { Volume of microspheres after tappin }}
$$

\section{Carr's compressibility index:}

This is an important property in maintaining uniform weight. It is calculated using following Equation,

$$
\text { Carr, } \mathrm{s} \text { Index }=\frac{\text { Tapped density }- \text { Bulk density }}{\text { Tapped density }} \times 100
$$

Table 4: Carr's compressibility index:

\begin{tabular}{|c|l|}
\hline Carr's (compressibility index) & Flowability \\
\hline $5-15$ & Excellent \\
\hline $12-16$ & Good \\
\hline $18-21$ & Fair to passable \\
\hline $23-35$ & Poor \\
\hline $33-38$ & Very poor \\
\hline$>40$ & Extremely poor \\
\hline
\end{tabular}

\section{Hausner's ratio:}

Hausner's ratio less than 1.25 indicates good flow and greater than 1.5 indicates poor flow whereas between 1.25 and 1.5 indicates glidant normally improves flow. Hausner's ratio can be calculated by formula,

$$
\text { Hausner, s Ratio }=\frac{\text { Tapped density }}{\text { Bulk density }}
$$

\section{Morphology study:}

Scanning Electron Microscopy (SEM) was performed to characterize the surface of formed beads. Beads were mounted directly onto the sample stub and coated with gold ion and analyze for surface morphology.

\section{Particle size analysis:}

The particle size of drug loaded formulations were measured by an optical microscope fitted with calibrated ocular and stage micrometer and particle size distribution was calculated. 50 particles in five different fields were examined.

\section{Determination of Percentage yield}

The prepared beads were collected and weighed. The measured weight was divided by the total amount of all non-volatile components, which were used for the preparation of the beads.

$$
\text { Percentage Yield }=\frac{\text { Actual weight of products }}{\text { Weight of drug and excipients }} \times 100
$$

\section{Drug Entrapment Efficiency}

Beads equivalent to $100 \mathrm{mg}$ of the drug were taken for evaluation. The amount of drug entrapped was estimated by crushing the beads and extracting with aliquots of $0.1 \mathrm{~N} \mathrm{HCl}$ repeatedly. The extract was transferred to a $100 \mathrm{ml}$ volumetric flask and the volume was made up using $0.1 \mathrm{~N} \mathrm{HCl}^{17}$. The solution was filtered and the absorbance was measured at suitable wavelength against appropriate blank. The amount of drug entrapped in the beads was calculated by the following formula,

Drug entrapment efficiency $=$ $\frac{\text { Amount of drug actually present }}{\text { Theoretical drug loaded expected }} \times 100$

\section{In vitro buoyancy study}

Beads (300mg) were spread over the surface of a USP XXIV dissolution apparatus type II filled with $900 \mathrm{ml}$ of $0.1 \mathrm{~N} \mathrm{HCl}$ containing $0.02 \%$ Tween 80 . The medium was agitated with a paddle rotating at $100 \mathrm{rpm}$ for $12 \mathrm{hr}$. The floating and the settled portions of beads were recovered separately. The beads were dried and weighed. Buoyancy percentage was calculated as the ratio of the mass of the beads that remained floating and the total mass of the beads.

$$
\% \text { Buoyancy }=\frac{Q f}{Q f+Q s} \times 100
$$

Where,

Qf = Weight of the floating Beads

Qs = Weight of settled Beads

\section{In-vitro drug release study}

The drug release study from beads is performed using USP dissolution apparatus Type I in $900 \mathrm{ml}$ of $0.1 \mathrm{~N}$ $\mathrm{HCl}$ dissolution media (pH- 1.2) at $100 \mathrm{rpm}$ and $37^{\circ} \mathrm{C} .2$ $\mathrm{ml}$ sample was withdrawn at $1 \mathrm{hr}$. time interval for $12 \mathrm{hr}$. and same volume of fresh medium was replaced to maintained sink condition. Withdrawn samples were assayed spectrophotometrically at suitable wavelength. The drug release was analyzed by UV spectrophotometer.

\section{Determination of Moisture Content}

The formulations were subjected to moisture content study by using an IR moisture balance by placing the beads at $60{ }^{\circ} \mathrm{C}$ for $10 \mathrm{~min}$.

\section{SEM of floating beads}

Morphological characterization of the floating alginate beads is done by taking scanning electron micrograph (Model Jeol JSM-5200) ${ }^{18}$. Cross-sectional views are obtained by cutting the bead with a razor blade. The samples were coated to $200 \mathrm{~A}^{\mathrm{o}}$ thickness with goldpalladium prior to microscopy. A working distance of 20 $\mathrm{nm}$, a tilt of $0^{\circ}$ and accelerating voltage of $15 \mathrm{KV}$ were the operating parameters. Photographs were taken within the range of 50- 500 magnifications.

\section{Application of floating drug delivery systems ${ }^{19}$}

Floating drug delivery offers several applications for drugs having poor bioavailability because of the narrow absorption window in the upper part of the gastrointestinal tract. It retains the dosage form at the site of absorption and thus enhances the bioavailability. These are summarized as follows:

1. Sustained drug delivery: FDDS can remain in the stomach for long periods and hence can release the drug over a prolonged period of time. The problem of short gastric residence time encountered with an oral CR formulation hence can be overcome with these systems. These systems have a bulk density of $<1$ as a result of which they can float on the gastric contents. These systems are relatively large in size and passing from the pyloric opening is prohibited. E.g. Sustained release floating capsules of Nicardipine Hydrochloride 
2. Site-specific drug delivery: These systems are particularly advantageous for drugs that are specifically absorbed from stomach or the proximal part of the small intestine. E.g. Riboflavin and Furosemide

3. Absorption enhancement: Drugs that have poor bioavailability because of site specific absorption from the upper part of the gastrointestinal tract are potential candidates to be formulated as floating drug delivery systems, thereby maximizing their absorption.

\section{Reduced fluctuations of drug concentration:}

Continuous input of the drug following Controlled Release administration produces blood drug concentrations within a narrower range compared to the immediate release dosage forms. Thus, fluctuations in drug effects are minimized and concentration dependent adverse effects that are associated with peak concentrations can be prevented. This feature is of special importance for drugs with a narrow therapeutic index.

5. Improved selectivity in receptor activation: Minimization of fluctuations in drug concentration also makes it possible to obtain certain selectivity in the elicited pharmacological effect of drugs that activate different types of receptors at different concentrations.

6. Maintenance of Constant Blood Level: These systems provide an easy way of maintaining constant blood level with an ease of administration and better patient compliance.

Recent advances in stomach specific floating dosage forms:

Sungthongjeen et al have prepared a floating multilayer coated tablets based on gas formation. The system consists of a drug containing core tablet coated with a protective layer (hydroxyl propyl methyl cellulose), a gas forming layer (sodium bicarbonate) and a gasentrapped membrane, respectively. Eudragit RL 30D was chosen as a gas-entrapped membrane due to its high flexibility and high water permeability ${ }^{20}$. The obtained tablets enabled to float due to the $\mathrm{CO} 2$ gas formation and the gas entrapment by polymeric membrane. The effect of formulation variables on floating properties and drug release was investigated. The floating tablets using direct compressed cores had shorter the time to float and faster drug release than those using wet granulated cores. The increased amount of a gas forming agent did not affect time to float but increased the drug release from the floating tablets, while increasing the coating level of gas entrapped membrane increased the time to float (more than 8 hours) and slightly retarded, but sustained drug release. Rajnikanth et al have developed a floating in situ gelling system of clarithromycin (FIGC) using gellan as gelling polymer and calcium carbonate as floating agent for potentially treating gastric ulcers, associated with Helicobacter pylori (H.pylori). Gellan based FIGC was prepared by dissolving varying concentrations of gellan in deionized water, to which varying concentrations of the drug and sucralfate were dispersed well ${ }^{30-35}$. The addition of sucralfate to the formulation significantly suppressed the degradation of clarithromycin at low $\mathrm{pH}$. FIGC showed a significant anti $H$. pylori effect than that of clarithromycin suspension $^{25}$. The in situ gel formulation with sucralfate cleared H.pylori more effectively than that of formulation without sucralfate. In addition, the required amount of clarithromycin for eradication of H.pylori was found to be less from FIGC than from the corresponding clarithromycin suspension. It was concluded that prolonged gastrointestinal residence time and enhanced clarithromycin stability resulting from the floating in situ gel of clarithromycin might contribute better for complete clearance of $H$. pylori than the corresponding clarithromycin suspension ${ }^{39-42}$.

\section{GRDDS-The Industrial Perspective}

Pharmacotherapy of various disease states can be amended by drug repurposing through GRDDS. Assessment of the effect of the fed and fasted condition on product performance should be necessary during initial development phases ${ }^{26}$. Dual working technology would be a possible way to overcome drawbacks associated with different GRDDS. Before development of a drug product, the principles of scale up and process validation must be considered to improve the quality and market availability of GRDDS. Knowledge of all regulatory aspects will help to deliver a product to the market within a reasonable timeframe and in a costeffective manner. Varieties of investigations have been done that lead to development of various GRDDS. However, only few can make way to market. These technologies show excellent in vitro results but fail to give desirable in vivo performance. Mucoadhesive and floating technologies are getting substantial attention and most of the drug products available in the market are based on the principle of these technologies. In consequence, dual working systems based on mucoadhesive and floating principles have more potential to increase industrial implementation of GRDDS and can improve the in vivo performance of the active moiety ${ }^{27}$. Furthermore, combination of mucoadhesion technology with floating technology can ameliorate loopholes associated with floating technology like floating lag time. In future, some more gastroretentive technologies can be combined to improve the gastric retention and to reduce the associated drawbacks GIP. Thus, market appearance of GRDDS can be improved by opting an appropriate drug and delivery system with incorporating all the relevant quality attributes $^{28}$. TABLE below gives an overview of technologies adopted by pharmaceutical companies to formulate GRDDS. 
TABLE 5: Technologies adopted for GRDDS

\begin{tabular}{|c|c|c|c|}
\hline Technology & Company & Product & $\begin{array}{l}\text { Active pharmaceutical } \\
\text { ingredient }\end{array}$ \\
\hline Bioadhesive tablets & Lupin, India & Xifaxan & Rifaximin \\
\hline $\begin{array}{lll}\begin{array}{l}\text { Floating } \\
\text { preparation }\end{array} & \text { liquid } & \text { alginate } \\
\end{array}$ & $\begin{array}{lll}\begin{array}{l}\text { Pierre } \\
\text { France }\end{array} & \text { Fabre Medicament, } \\
\end{array}$ & Topalkan & $\begin{array}{l}\text { Aluminium magnesium } \\
\text { antacid }\end{array}$ \\
\hline $\begin{array}{ll}\text { Polymer-based } & \text { swelling } \\
\text { technology: AcuForm__ } & \end{array}$ & Depomed, Inc., USA & Gabapentin GR & Gabapentin \\
\hline $\begin{array}{l}\text { Coated multi-layer floating and } \\
\text { swelling system }\end{array}$ & Sun Pharma, India & Baclofen GRS & Baclofen \\
\hline
\end{tabular}

\section{CONCLUSION}

The identification of new diseases and the resistance shown towards the existing drugs felt the need for the introduction of new therapeutic molecules ${ }^{35}$. In response, a large number of chemical entities have been introduced, of which some have absorption all over the GIT and others have absorption windows in the upper part of the small intestine. The drugs that are required for local action in the GIT require a specialized delivery system which has been achieved by FDDS. A number of FDDS have been developed such as single and multiple

\section{REFERENCES}

1. Chugh C, Nanda A. Gastroretentive drug delivery systems - A review. Int J pharma bio sci. 2017; 8(1): 62- 68.

2. Porwal A, Dwivedi H, Pathak K. Decades of research in drug targeting using gastroretentive drug delivery systems for antihypertensive therapy. Brazilian J Pharma Sci. 2017; 53(3):1-15.

3. Anucharishma G, Hemalatha K, Swapna K. Raft Forming Drug Delivery Systems: A Review. Chronicles Pharma Sci.2017; 1(3):135-148.

4. Gayathridevi M, Adlin JN, Tamizh M. Floating microsphere: A review. Int J research in pharma and chem.2016; 6(3):501510.

5. Chintanippula Sai, Rao R, Sharath K, Kowmudi V. Development and In-Vitro Evaluation of Cefpodoxime Proxetil Gastro-Retentive Floating Tablets. Int J Applied Pharma Sci Research 2016, 1(1):31-41.

6. Yadav VD, Babar SA, SatheshkumarS. Formulation and Evaluation of Floating Beads of Norfloxacin. IOSR J Pharma, 2016, 6(9), Version.1:07-13.

7. Neeta, Mehta M, Satija S. Relevance of ionotropic gelation technique in the development of floating multiparticulate drug delivery systems. Int J Adv Sci Research, 2016, 1(4), 54-59.

8. Kashid P, Doijad R, Shete A, Sajane S, Bhagat A, Studies on Rebamipide Loaded Gastroretentive Alginate Based Mucoadhesive Beads: Formulation and In-vitro, In-vivo Evaluation, Pharma Methods,2016, 7(2),132-138.

9. Ayre A, Dand N, Lalitha KG. Gastro-retentive Floating and Mucoadhesive Drug Delivery Systems- Insights and Current Applications, IOSR J Pharma and Bio Sci. 2016, 11(3) Ver. I. 89-96.

10. Abraham S, Muhammed N, Peter V. Formulation and evaluation of gastro-retentive drug delivery system containing combination of glipizide and metformin hydrochloride. Asian J Pharma and Clinical Research,2016, 9(6), 235-240.

11. Felix Sunday Yusuf. Formulation and in-and evaluation of floating microballoons of stavudine. Universal Journal of Pharmaceutical Research. 2016, 1(1), 13-19.

12. Nethaji R, Narayanan A, Palanivelu M. Formulation and Evaluation of metformin hydrochloride loaded mucoadhesive microspheres. Int J Pharma, Chem and Bio Sci. 2016, 6(2), 124-132. unit HBS, single and multiple unit gas generating systems, hollow microspheres and raft forming systems. Development of sustained release formulations is advantageous in providing prolonged gastric retention and increased efficacy of the dosage forms ${ }^{40-44}$. The floating behavior of the low density drug delivery systems could successfully be combined with accurate control of the drug release patterns in order to boast accurate bioavailability. Hence further studies are needed in this regard in order to encompass effective drug delivery systems.

13. Kumari R, Verma N, Chaudhary N. Gastro Retentive Floating Microspheres a New Trend of Drug Delivery System, Int J Adv Research and Innovation. 2015, 3(2), 459-467.

14. Patil Chandrashekar, Indikar Kousarbanu, Bhaskar Umarji, Formulation and Evaluation of Gastroretentive Floating Beads of Cefuroxime Axetil, Res J Pharm and Tech. 2015, 8(1), 13-19.

15. Kumar AB, Mahalakshmi K, Rao MVU: Formulation and Evaluation of Gastro Retentive Floating Microbeads of Sumatriptan, Int J Life Sci and Review. 2015;1(4), 137-143.

16. Kakar S, Singh R, Shallusandhan. Gastroretentive drug delivery systems: A review, African J Pharma and Pharmacology. 2015, 9(12), 405-417

17. Parsekar SD, Prabhu S, Shetty A. A Brief Review on Floating Bilayer Tablet as a Convenient Gastro-retentive Drug Delivery System. Int J Pharmal and Chemical Sci. 2014, 3 (2), 420-430.

18. Asija R, Sharma D, Mali KR. Solvent evaporation matrix erosion method: a novel approach for floating microsphere development. J Drug Discovery and Therapeutics. 2014, 2 (21), 24-29.

19. Verma R, Devre Kishor, Gangrade Tushar, Bi-layer tablets for various drugs: A review, Scholars Academic J Pharma. 2014, 3(3), 271-279.

20. Ikechukwu UR, John Francis DE, Ambi AA. Development and evaluation of hitonavir hollow microballoons for floating drug delivery. Universal Journal of Pharmaceutical Research. 2017, 2(2), 30-34.

21. Mishra J, Kumar DA. Recent advances in gastro retentive drug delivery system: a review, Mintage J Pharma and Med Sci. 2013, 2(2), 25-27.

22. Chauhan Parth, Patel MS, Patel NM, Review on gastroretentive drug delivery systems, Ind J Drugs and Diseases. 2013, 2(10), 218-230.

23. Kumar NA, Pal D, Malakar J. Development, optimization, and evaluation of emulsion-gelled floating beads using natural polysaccharide-blend for controlled drug release, Polymer Engineering and Science. 2013, 53(2), 238-250.

24. Geetha A, Rajendra kumar J, Krishna M. A review on floating drug delivery systems, Int J Pharma Res and Biomed Analysis. 2012, 1(1), 1-13.

25. Sandina S, Allena RT, Gowda DV. A Comprehensive review on gastroretentive drug delivery systems, int $\mathrm{j}$ res pharma and biomed Sci. 2012, 3 (3), 1285-1293. 
26. Binoy B, Jayachandran Nair CV. Floating drug delivery system- A new approach in gastric retention- A review, J Drug Delivery Res. 2012, 1(3), 18-31.

27. Pandey A, Kumar G, Kothiyal P, Barshiliya Y. A Review on current approaches in gastro retentive drug delivery system. Asian J Pharma and Med Sci. 2012, 2 (4), 60-77.

28. Igwe J. Chibueze, Emenike IV, Oduola AR. Formulation and evaluation

Finasteride sustained-release matrix tablets using different rate controlling

polymers. Universal Journal of Pharmaceutical Research. 2016, 1(2), 25-31.

29. Awasthi R, Kulkarni T. Development of Novel Gastroretentive Floating Particulate Drug Delivery System of Gliclazide, Current Drug Delivery,2012, 9(5), 437-451.

30. Biswas SK, Paul S, Chowdhury A, Das J. Preparation and Evaluation of Gastroretentive Floating Pellets of Metronidazole Using Na-alginate and Hydroxyl Propyl Methyl Cellulose Polymers, Pak J Bio Sci. 2012, 15,290-295.

31. Pandya K., Aggarwal P., Dashora A., Sahu D., Garg R., Pareta L., Menaria M., Joshi B. Formulation and evaluation of oral floatable in-situ gel of ranitedine hydrochloride. Journal of Drug Delivery and Therapeutics, 2013; 3(3):90-97. doi:10.22270/jddt.v3i3.516

32. Kapil K, Rai AK. Development and evaluation of floating microspheres of herbal drugs, Tropical J Pharmaceutical Research. 2012: 11(5), 713-719.

33. Anyanwu NCJ, Adogo LY, Ajide B. Development and evaluation of in situ gelling gastroretentive formulations of Meloxicam. Universal Journal of Pharmaceutical Research. 2017, 2(3), 11-14.

34. Shinde S, Tadwee I, Shahi S. Gastro retentive Drug Delivery System: A Review, Int J Pharma Res and Allied Sci. 2011, 1(1), 01-13.
35. Parkash V, Jogpal V, Maan S. A review on gastroretentive drug delivery system, Int J Pharma and Life Sci. 2011, 2(5), 773-781.

36. Kappor D., Patel M., Vyas R., Lad C., Tyagi B. A review on microsponge drug delivery system. Journal of Drug Delivery and Therapeutics, 2014; 4(5):29-35. doi: $10.22270 /$ jddt.v4i5.978

37. Gannu P, Jannu A. Porous floating microspheres: A new dimension in controlled drug delivery, Res J Pharma and Tech. 2011, 4(9), 1340-1357.

38. Rastogi V., Shukla S., Singh R., Lal N., Yadav P. Microspheres: a promising drug carrier. Journal of Drug Delivery and Therapeutics, 2016; 6(3):18-26. doi:10.22270/jddt.v6i3.1196

39. Pradeep K. Nimase, Vidyasagar G. Preparation and evaluation of floating calsium alginate beads of Clarithromycin, Pelagia Research Library. 2010, 1(1), 29-35.

40. Kumar K, Pant NC, Ahmad S, Fateh MV, Rai AK, Verma B, Chaurasia H. Development and evaluation of floating microspheres of curcumin in alloxan induced diabetic rats, Tropical Journal Pharmaceutical Research. 2016, 15 (9), 18191825.

41. Jain P., Jain D. Development of clarithromycin gastroretentive microspheres. Journal of Drug Delivery and Therapeutics, 2017; 7(7):81-83. doi:10.22270/jddt.v7i7.1594

42. Vedhahari. The recent developments on gastric floating drug delivery systems: an Overview. Int J Pharm Res. 2010; 2(1), 524-534.

43. Garg R, Gupta GD, Progress in Controlled Gastroretentive Delivery Systems. Trop J Pharma Res, 2008, 7 (3): 1055-1066.

44. Kumar K, Rai AK. Floating Microsphere: An innovative Approach for Gastro retention, Journal of Pharmacy Research. 2012; 5(2):883-886. 